\title{
Case Report: Successful Management of an Aluminum Phosphide Poisoned Patient Following Ventricular Tachycardia
}

\author{
Shahin Hallaj ${ }^{1}$ (D), Ali Banagozar Mohammadi² (D, Anahita Ghorbani' ${ }^{1}$ (D), Ali Ostadi² (D, Maryam Zaare Nahandi ${ }^{* *}$ (D) \\ 1. Student Research Committee, Tabriz University of Medical Sciences, Tabriz, Iran. \\ 2. Department of Internal Medicine, Sina Educational, Research and Treatment Center, School of Medicine, Tabriz University of Medical Sciences, \\ Tabriz, Iran.
}

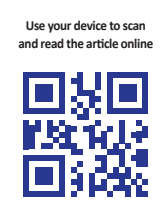

Citation: Hallaj S, Banagozar Mohammadi A, Ghorbani A, Ostadi A, Zaare Nahandi M. Successful Management of an Aluminum Phosphide Poisoned Patient Following Ventricular Tachycardia. International Journal of Medical Toxicology and Forensic Medicine. 2020; 10(4):30473. https://doi.org/10.32598/ijmtfm.v10i4.30473

https://doi.org/10.32598/ijmtfm.v10i4.30473

Article info:

Received: 15 May 2020

First Revision: 20 May 2020

Accepted: $01 \mathrm{Jul} 2020$

Published: 23 Nov 2020

\section{Keywords:}

Tachycardia, Ventricular, Aluminum phosphide, Heart, Antioxidants

\section{A B S T RACT}

Aluminum Phosphide (ALP) poisoning is regarded as fatal; however, it is commonly used in developing countries. In some countries, such as India and Iran, it is still being used to protect grain against pests at home. As yet, no known antidote is reported to be effective against ALP poisoning. ALP acts through blockage of cell respiration, alteration of cell permeability, and induction of oxidative stress. Some factors can worsen the prognosis of its intoxication, which include hyperglycemia on admission, ingestion of fresh tablets, cardiac abnormality, especially Ventricular Tachycardia (VT), severe metabolic acidosis, cardiogenic shock and other types of shocks, electrolyte disturbances, end-organ damage, and a need for mechanical ventilation. ALP kills its victims by induction of multi-organ failure.

In this study, we controlled the patient's VT using MgSO4, electric shock, amiodarone, and lidocaine. We also encountered the cardiogenic shock using norepinephrine, High-Dose Insulin (HDI), antioxidants, sodium bicarbonate, and normal saline. Moreover, myocardial ischemia, recurrent VTs, and adverse cardiac effects were protected via tight control of magnesium and other electrolytes.

\section{Introduction}

luminum Phosphide (ALP), commonly A known as rice pill or wheat pill in Iran, an insecticide and rodenticide, which is used in the grain processing industries, is commonly recognized for its dramatic human intoxication, as it kills $37-100 \%$ of its vic- tims [1]. With such a high mortality rate and its widespread use in developing countries, such as India and Iran, ALP poisoning is known as the main cause of death in toxicology wards and Intensive Care Units (ICUs) [2]. When ALP enters the body through ingestion or inhalation, it interacts with the water or hydrochloric acid molecules and produces the phosphine gas. This substance can act through blockage of the cell respiration, inhibi-

* Corresponding Author:

Maryam Zaare Nahandi, MD.

Address: Department of Internal Medicine, Sina Educational, Research and Treatment Center, School of Medicine, Tabriz University of Medical Sci-

ences, Tabriz, Iran.

Tel: +98 (41) 35498260

E-mail:dr_mzaare@yahoo.com; zaarem@tbzmed.ac.ir 
tion of cytochrome, protein synthesis blockage, production of reactive oxygen species and alter the permeability of the cell membranes.

These mechanisms affect the heart, kidneys, liver, as well as lungs and lead to end-organ failures. Cardiac toxicity includes all kinds of arrhythmias e.g. Ventricular Tachycardia (VT), electrocardiogram (ECG) abnormalities, Heart Failure (HF), and myocarditis [3, 4]. VT in these patients is treated by amiodarone and Magnesium Sulfate (MgSO4), but it is still known as an indicator of poor prognosis among ALP poisoned patients [5]. Several case report studies have indicated the successful cardioversion from VT to the sinus rhythm using MgSO4 and amiodarone [6]. Although using lidocaine could cardiovert patients with VT rhythm to sinus rhythm, in some other studies, it could not be cardioverted [7]. As there is a limited number of surveys to address the effectiveness of these drugs, efficacy and failure rate of them are under question.

Many studies have reported hypomagnesemia following ALP intoxication and suggested maintaining a eumagnasemic state as a cornerstone for the treatment of cardiac manifestations of ALP intoxication. It can affect through restoring the glutathione storage and suppressing ALP-induced oxidative stress. Due to its autonomic modulatory, antioxidant, and membrane stabilizer effects, it could significantly reduce the mortality rate in several human studies $[8,9]$.

This study presented a rare case of successful management of an Aluminium phosphide poisined patient following VT and cardiogenic shock, who was discharged successfully from the hospital one month after intoxication with negligible complication.

\section{Case Presentation}

A 13-year-old girl, with no history of surgical, medical, or psychological disorders, was admitted to the emergency ward of "Sina Hospital" (toxicology center of North-West Iran). Her mother had a complaint about the gradual loss of her daughter's consciousnesses, following vomiting and diarrhea after ingestion of two ALP tablets $(6 \mathrm{~g})$ at the school. The purpose of the act was uncertain. At the emergency ward, a blood pressure of $95 / 50 \mathrm{mmHg}$, pulse rate of $115 \mathrm{bpm}$, a body temperature of $37^{\circ} \mathrm{C}$, and blood sugar of $198 \mathrm{mg} / \mathrm{dL}$ were recorded for her. Due to the loss of consciousness (GCS:7), she underwent Rapid sequence intubation; thus, we could secure her airways and prevent aspiration. At the emergency ward, sodium bicarbonate $(100 \mathrm{mEq})$, calcium gluconate (1 g), vitamin C (1 g), vitamin D (300,000 IU), vitamin $\mathrm{E}$ (400 IU), $\mathrm{KCl}(20 \mathrm{mEq})$, and serum normal saline $(1 \mathrm{~L})$ were added to her orders.

Subsequently, she was admitted to the toxicology ICU with the diagnosis of ALP poisoning. During her stay in ICU, she was sedated with fentanyl and ventilated with a mechanical ventilator. Because of severe hypovolemic and cardiogenic shock, we tried to correct metabolic acidosis and shock with norepinephrine (10 $\mu \mathrm{g} / \mathrm{min})$, hydrocortisone (200 $\mathrm{mg}$ stat and $100 \mathrm{mg}$ every $6 \mathrm{~h}$ ), normal saline ( $1 \mathrm{~L}$ stat and $1 \mathrm{~L}$ every $4 \mathrm{~h}$ ), sodium bicarbonate (100 mEq in each 11 serum), N- acetylcysteine (300 mg/ $\mathrm{kg}$ in $1 \mathrm{~L}$ serum dextrose water $5 \%$ daily), magnesium sulfate $(1 \mathrm{~g}$ every $6 \mathrm{~h})$, calcium gluconate $(1 \mathrm{~g}$ every 6 $\mathrm{h}$ on the first day and $1 \mathrm{~g}$ every $4 \mathrm{~h}$ in next days), and High-Dose Insulin (HDI) $(1 \mathrm{u} / \mathrm{kg}$ regular insulin plus $1 \mathrm{~g} / \mathrm{kg}$ glucose $50 \%$ stat and $0.5 \mathrm{u} / \mathrm{kg} / \mathrm{h}$ regular insulin plus $0.5 \mathrm{~g} / \mathrm{kg} / \mathrm{h}$ glucose $50 \%$ ) infusion via central venous line. Also, because of rapidly progressive hypovolemic shock, three units of iso-group Fresh Frozen Plasma (FFP) was administered on the first day.

Eight hours after admission, she experienced pulseless Ventricular Tachycardia (VT). Therefore, a $200 \mathrm{~J}$ unsynchronized electric shock was given to her. Also, lidocaine (100 mg, stat), 500cc normal saline serum, and $100 \mathrm{mEq}$ sodium bicarbonate were infused; but an hour after recovery of the first VT, she experienced the second VT; thus, another $200 \mathrm{~J}$ unsynchronized electric shock was given again. Following the second electric shock, the sinus rhythm and her pulses came back. Afterward, amiodarone (150 mg in first $10 \mathrm{~min}, 360 \mathrm{mg}$ during the next 6 $\mathrm{h}$ and $540 \mathrm{mg}$ during subsequent $18 \mathrm{~h}$ ) was prescribed.

Ten days after admission, we noted inversion of the Twaves in her daily ECGs (leads: II, III, aVf, V3, V4, V5, V6) followed by Non-Sustained VT (NSVT). We kept her serum potassium levels at $4 \mathrm{mEq} / \mathrm{L}$, magnesium levels at $2 \mathrm{mg} / \mathrm{dL}$, and then a cardiology counsel was requested.

The cardiologist started 25mg of metoprolol, 20mg of atorvastatin, and $80 \mathrm{mg}$ of aspirin on a daily basis because the myocardium was suffering from ALP-induced hypoxia. Afterward, it was observed that her body temperature rose to $40^{\circ} \mathrm{C}$, heavy tracheal discharges were produced, and coarse crackles were heard from her lungs. Chest X-ray was taken and consultation with the infectious diseases service was asked for, and antibiotic therapy was started, as they suspected Ventilator-Associated Pneumonia (VAP) -induced septicemia. We only detected enterococcus in her urine culture and MethicillinSensitive Staphylococcus Aureus (MSSA) in her blood culture for two subsequent times. In her tracheal aspi- 
Table 1. Brief results of the lab tests of the Aluminum Phosphide (ALP) intoxicated patient

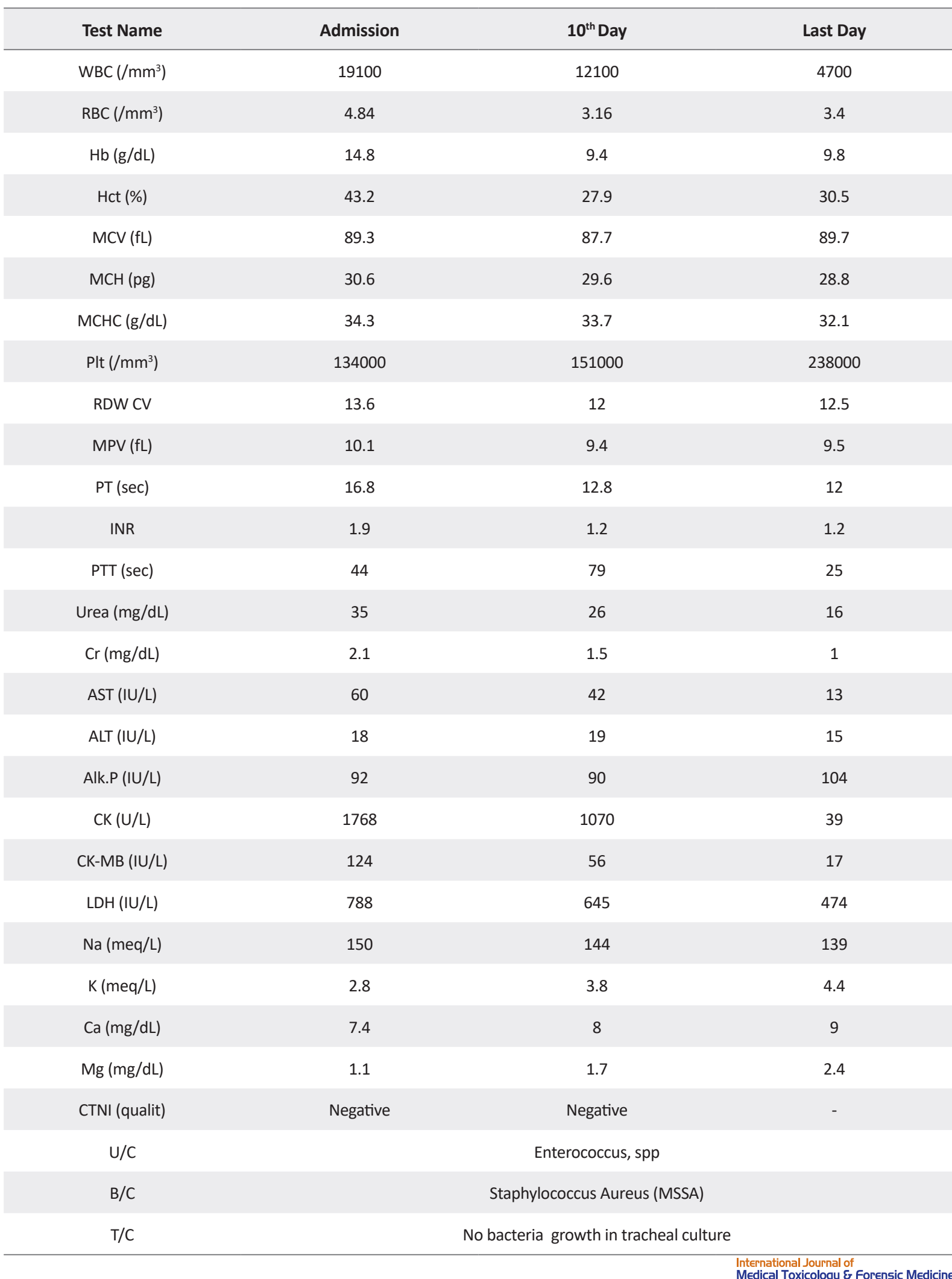

ration culture, no bacteria growth was detected. During her admission, serial Arterial Blood Gas tests (ABGs) were taken to control the metabolic acidosis, ventilation status and to set the mechanical ventilator. Her total cal- 
cium levels were either kept above $8-9$, or her ionized calcium kept above $1.2 \mathrm{mg} / \mathrm{dL}$ using calcium gluconate. On day 15, two units of the packed red blood cells were administered as her hemoglobin levels fell below $7 \mathrm{~g} / \mathrm{dL}$.

On day 17, we tapered the sedatives as her ABGs, and clinical findings were improved. The next day she was extubated.

She was discharged on her $27^{\text {th }}$ day of admission, after assuring normal lab test results and clinical findings (Table 1). However, 25 days after discharge, she was admitted with the diagnosis of mild tracheal stenosis and undergone tracheal dilation (Broncoplasty) with rigid bronchoscopy and successfully discharged again. The lab tests and clinical findings were normal in her 24-months follow-up visits and the patient did not have any complication.

\section{Discussion}

ALP poisoning is regarded as fatal; however, it is commonly used in developing countries. In some countries, such as India and Iran, it is still being used to protect grain against pests at home. Some factors are known to improve the prognosis of ALP intoxication, which include younger age, ALP gas aspiration, drinking of ALP solution instead of tablet ingestion, vomiting following ingestion, and/or low-dose ingestion. On the other hand, some factors can worsen the prognosis of its intoxication, including hyperglycemia on admission, ingestion of fresh tablet, cardiac abnormality, especially VT, severe metabolic acidosis, cardiogenic shock and other types of shocks, electrolyte disturbances, other end-organ damages, and a need for mechanical ventilation [2, 4-7]. By induction of multi-organ failure, ALP kills its victims. Furthermore, the myocardium is regarded as one of the most critical targets of ALP. Cardiac toxicity induced by ALP includes all kinds of arrhythmias e.g. VT, ECG abnormalities, HF, and myocarditis, of which VT is considered as a factor indicating poor prognosis and death.

In this study, we controlled the patient's VT using electric shock, amiodarone, and lidocaine, in addition to previously prescribed continuous prophylactic MgSO4 [10, 11]. We also encountered the cardiogenic shock using norepinephrine, HDI, antioxidants, sodium bicarbonate, and normal saline. However, myocardial ischemia, recurrent VTs, and adverse cardiac effects were protected via tight control of magnesium and other electrolytes [10, 11].

Overall, our case report could indicate the effectiveness of the simultaneous usage of electric shock, amiodarone, lidocaine, and MgSO4. Additionally, it was found that prescribing $\mathrm{MgSO} 4$ and tight control of serum electrolytes and acid-base disturbances are beneficial for the management of ALP poisoned patients. However, more clinical studies are needed to prove or decline these suggestions.

To conclude, it is only recommended that these drug interventions should be prescribed based on patients' clinical conditions, in addition to the treatment of patients' dysrhythmias with standard protocols.

\section{Ethical Considerations}

\section{Compliance with ethical guidelines}

All ethical principles were considered in this article. All procedures performed in this study were in accordance with the ethical standards of the institutional and or national research committee and with the $1964 \mathrm{Hel}$ sinki declaration and its later amendments.

\section{Funding}

This research did not receive any specific grant from funding agencies in the public, commercial, or not-forprofit sectors.

\section{Author's contributions}

All authors contributed to all process of the article preparation. Also, all authors reviewed and revised the manuscript several times.

\section{Conflict of interest}

The authors declare no conflict of interest

\section{Acknowledgements}

We would like to thank the Clinical Research Development Unit of Sina Educational, Research and Treatment Center, Tabriz University of Medical Sciences, Tabriz, Iran; for their assistance in this research.

\section{References}

[1] Sulaj Z, Drishti A, Çeko I, Gashi A, Vyshka G. Fatal aluminum phosphide poisonings in Tirana (Albania), 2009-2013. DARU J Pharm Sci. 2015; 23(1):8. [DOI:10.1186/s40199-0150090-0] [PMID] [PMCID]

[2] Hosseinian A, Pakravan N, Rafiei A, Feyzbakhsh S. Aluminum phosphide poisoning known as rice tablet: A com- 
mon toxicity in North Iran. Indian J Med Sci. 2011; 65(4):143. [DOI:10.4103/0019-5359.104777] [PMID]

[3] Türkez H, Toğar B. Aluminum phosphide-induced genetic and oxidative damages in rats: Attenuation by Laurus nobilis leaf extract. Toxicol Ind Health. 2013; 29(7):579-83. [DOI:10.1177/0748233711433942] [PMID]

[4] Anand R, Binukumar BK, Gill KD. Aluminum phosphide poisoning: An unsolved riddle. J Appl Toxicol. 2011; 31(6):499-505. [DOI:10.1002/jat.1692] [PMID]

[5] Taghaddosi Nejad F, Banagozar Mohammadi A, Behnoush B, Kazemifar A, Zaare Nahandi M, Dabiran S, Jamalian M. Predictors of poor prognosis in aluminum phosphide intoxication. Iran J Toxicol. 2012; 6(16):610-4.http://ijt.arakmu. ac.ir/article-1-122-en.html

[6] Changal KH, Latief M, Parry M, Abbas F. Aluminium phosphide poisoning with severe cardiac dysfunction and the role of digoxin. Case reports. Glob Health. 2017; 2017. [DOI:10.1136/bcr-2017-220125] [PMID] [PMCID]

[7] Beyranvand MR, Farrokhi S, Peyvandi H, Soltaninejad K, Shadnia S. The effects of amiodarone prophylaxis on cardiac dysrhythmia in acute aluminium phosphide poisoning. Arh Hig Rada Toksikol. 2019; 70(1):49-53. [DOI:10.2478/aiht-201970-3162] [PMID]

[8] Mehrpour O, Jafarzadeh M, Abdollahi M. A systematic review of aluminium phosphide poisoning. Arh Hig Rada Toksikol 2012; 63(1):61-73.[DOI:10.2478/10004-1254-63-2012-2182] [PMID]

[9] Jafari A, Baghaei A, Solgi R, Baeeri M, Chamanara M, Hassani $\mathrm{S}$, et al. An electrocardiographic, molecular and biochemical approach to explore the cardioprotective effect of vasopressin and milrinone against phosphide toxicity in rats. Food Chem Toxicol. 2015; 80:182-92. [DOI:10.1016/j.fct.2015.02.022] [PMID]

[10] Baruah U, Sahni A, Sachdeva HC. Successful management of aluminium phosphide poisoning using intravenous lipid emulsion: Report of two cases. Indian J Critical Care Med 2015; 19(12):735. [DOI:10.4103/0972-5229.171412] [PMID] [PMCID]

[11] Karimani A, Mohammadpour AH, Zirak MR, Rezaee R, Megarbane B, Tsatsakis A, et al. Antidotes for aluminum phosphide poisoning-an update. Toxicol Rep. 2018; 5:1053-9. [DOI:10.1016/j.toxrep.2018.10.009] [PMID] [PMCID] 
This Page Intentionally Left Blank 